\title{
1 Subsoil arbuscular mycorrhizal fungal communities in arable soil differ from
}

\section{2 those in topsoil}

3 Moisés A. Sosa-Hernández ${ }^{1,2}$, Julien Roy ${ }^{1,2}$, Stefan Hempel $^{1,2}$, Timo Kautz $^{3}$, Ulrich

4 Köpke $^{3}$, Marie Uksa ${ }^{4,5}$, Michael Schloter ${ }^{5,6}$, Tancredi Caruso ${ }^{7}$, Matthias C. Rillig ${ }^{1,2^{*}}$.

$5{ }^{1}$ Institute of Biology, Plant Ecology, Freie Universität Berlin, Berlin, Germany

$6 \quad{ }^{2}$ Berlin-Brandenburg Institute of Advanced Biodiversity Research, Berlin, Germany

$7{ }^{3}$ Institute of Organic Agriculture, University of Bonn, Bonn, Germany

$8{ }^{4}$ Institute of Soil Science and Land Evaluation, Soil Biology, University of Hohenheim,

9 Stuttgart, Germany

$10{ }^{5}$ Research Unit for Comparative Microbiome Analysis, Helmholtz Zentrum München,

11 Neuherberg, Germany

$12{ }^{6}$ Chair for Soil Science, Technische Universität München, Freising, Germany

$13{ }^{7}$ School of Biological Sciences and Institute for Global Food Security, Queen's

14 University of Belfast, Belfast, Northern Ireland (UK)

17 * Correspondence to Moisés A. Sosa Hernádez, Freie Universität Berlin, Plant Ecology,

18 Altensteinstr.6, D-14195 Berlin, Germany; Email: moisessh@zedat.fu-berlin.de Tel.

$19+49(0) 30838-53143$

20 


\section{Abstract}

22 Arbuscular mycorrhizal fungi are recognized as important drivers of plant health

23 and productivity in agriculture but very often existing knowledge is limited to the

24 topsoil. With growing interest in the role of subsoil in sustainable agriculture, we

44 strategies. 
45 Previous studies have shown that AMF spore abundance and diversity in agricultural

46 fields decrease with soil depth (Muleta et al., 2008; Oehl et al., 2005; Yang et al.,

47 2010), however under some circumstances subsoil spore diversity may be greater than

48 in the topsoil (Oehl et al., 2005). Moreover, some species' spores seem to be

49 associated with particular soil layers, suggesting a vertical variation in community

50 composition (Muleta et al., 2008; Oehl et al., 2005; Yang et al., 2010). These spore-

51 based results have recently been supported by small ribosomal subunit (SSU) cloning-

52 sequencing approaches, finding differences in community composition between AMF

53 communities at different depths (Moll et al., 2016). Nonetheless, we are just starting to

54 unearth subsoil AMF diversity, and the community assembly processes remain

55 unknown.

56 To shed light on subsoil AMF communities, we used Illumina MiSeq sequencing to

57 analyze a set of soil samples encompassing drilosphere (soil directly influenced by

58 earthworms), rhizosphere (soil directly influenced by roots) and bulk soil (without roots

59 or earthworm burrows), in both top- $(10-30 \mathrm{~cm}$, i. e. above the ploughing layer) and

60 subsoil $(60-75 \mathrm{~cm})$. Sampling the different compartments was intended to add greater

61 resolution to our results. The first $10 \mathrm{~cm}$ were not sampled due to difficulties in

62 differentiating the mentioned compartments at this depth. Samples were collected in

63 May 2011 in a field planted with Cichorium intybus L. (see Uksa et al. (2014) for

64 details).

65 We performed amplicon-based AMF specific metabarcoding using the AMF specific

66 primer sets described in Krüger et al. (2009) and the primers LR3 and LR2rev

67 (Hofstetter et al., 2002). The final product of amplification is a 350-440 bp region in the

68 LSU including the variable D1-D2 region. Samples were paired-end sequenced on an

69 Illumina MiSeq platform. Bioinformatics details are given in the supplementary material.

70 Briefly, following quality filtering and chimera removal, sequences were de novo 
71 clustered at a $97 \%$ similarity level into operational taxonomic units (OTUs).

72 Representative sequences of these OTUs have been deposited at ENA under 73 accession numbers LT855246-LT855309.

74 Taxonomic assignment of the OTUs was carried out using BLAST+ (Camacho et al., 75 2009) against Glomeromycotina (i.e. AMF) reference sequences published in Krüger et 76 al. (2009) and against the EMBL nucleotide database (Kanz et al., 2005). Following a 77 similar approach as in Martínez-García et al. (2015) for SSU sequences, we 78 considered matches with $\geq 97 \%$ similarity a species level match, $\geq 90 \%$ a genus level 79 match, $\geq 80 \%$ a family level match and $\geq 70 \%$ a subphylum level match. A species level 80 match refers to how confidently we assign a name to our OTU based on known 81 sequences, and does not imply that these OTUs are to be considered equivalent to 82 those species. In total, 64 OTUs were confidently assigned to the subphylum 83 Glomeromycotina. Of these, we were able to assign 11 OTUs at the species level, 34 84 at the genus level, 16 at the family level and 3 at the subphylum level.

85 The resulting OTU table was analyzed with $\mathrm{R}$ version 3.3.1 (R Core Team, 2016).

86 Relative abundance data were obtained by rarefaction of all the samples to the lowest 87 number of reads in a sample (34377 reads), by random subsampling without 88 replacement. Details on the analyses are given in the supplementary material.

89 Our results present high-throughput molecular evidence that the subsoil AMF 90 community is not simply a subset of the topsoil community, but harbors unique OTUs 91 and that the two soil depths differ in structure both at the family level (Fig. 1) and at the 92 OTU level (Fig. 2). We detected 64 Glomeromycotina OTUs belonging to 7 families 93 (Ambisporaceae, Archaeosporaceae, Claroideoglomeraceae, Diversisporaceae, 94 Gigasporaceae, Glomeraceae and Paraglomeraceae, Table S1). OTU accumulation 95 curves for both top- and subsoil reached a plateau, indicating that we captured the 96 majority of the diversity (Fig. S2). We observed a highly significant community shift 
97 when comparing the top- and the subsoil (PERMANOVA, $F_{1,16}=8.67, P<0.001$, Fig. 3 ).

98 Most remarkably, Claroideoglomeraceae and Diversisporaceae exhibit inversely

99 proportional relative abundances across the studied soil profiles (Fig. 1). In topsoil

100 OTUs assigned to Diversisporaceae represented $41.8 \%$ of the reads whereas in

101 subsoil they represented $7.3 \%$ (GLM, $\left.F_{1,15}=50.83 \quad P<0.001\right)$. Conversely, OTUs

102 assigned to Claroideoglomeraceae represented $15.0 \%$ of the reads in topsoil but

$10359.9 \%$ in subsoil (GLM, $\left.F_{1,15}=17.87 P<0.001\right)$. The greater relative abundance of the

104 family Claroideoglomeraceae in subsoil is not correlated with its nominal diversity but

105 with a modest increase in relative richness (Fig. S3a,b). This finding may point to some

106 species in the Claroideoglomeraceae family being subsoil specialists and particularly

107 dominant in this compartment. This hypothesis is supported by previous results where

108 Claroideoglomus etunicatum spores were more commonly found in deeper soil layers

109 (Oehl et al., 2005; Yang et al., 2010). Conversely, both nominal and relative diversity in

110 the Diversisporaceae decreased in subsoil showing no evidence for specialization in

111 subsoil within this family. The family Glomeraceae however, is detected at a mostly

112 constant relative abundance across topsoil (34.1\%) and subsoil (28.4\%), but decreases

113 in abundance from rhizosphere $(49.0 \%)$ to bulk soil and drilosphere considered

114 together (23.6\%; GLM, $\left.F_{1,15}=6.79 P=0.02\right)$ (Fig. 1). Members of the Glomeraceae are

115 known to preferentially allocate biomass inside the root while producing limited

116 biomass in the soil (Powell et al., 2009). Our observations broadly support the idea

117 that, due to producing a limited extraradical mycelium, Glomeraceae species are

118 expected to preferentially colonize the direct surroundings of the root and to rapidly

119 decrease in abundance outside the rhizosphere. We hypothesize that species with a

120 preferentially intraradical lifestyle are less responsive to abiotic factors outside the root

121 and therefore can readily colonize different soil horizons. In turn, those intraradical

122 lifestyles would be mostly affected by host characteristics. 
123 In our subsoil samples OTU richness $(27.4 \pm 5.9)$ was significantly lower than in topsoil

124 (41.6 $\pm 6.0 ;$ GLM, $\left.F_{1,15}=23.83 P<0.001\right)$. Nonetheless we detected a total of 49 OTUs in

125 subsoil, with two OTUs (OTU_40 subphylum Glomeromycotina and OTU_68 genus

126 Glomus) exclusively found in the subsoil, also before normalization (data not shown).

127 Agricultural soils are subjected to a set of disturbances including fertilization or plant

128 removal during harvest; topsoils are additionally subjected to high disturbance in form

129 of tillage, negatively influencing AMF diversity (Kabir, 2005). Applying the C-S-R

130 (competitor, stress tolerator, ruderal) framework to AMF (Chagnon et al., 2013), we

131 would expect topsoil to be dominated by more ruderal species (i.e. elevated growth

132 rates, rapid and abundant spore production, etc.) and subsoil by stress tolerators (i.e.

133 low growth rates, long lived mycelium, etc.). We believe this may be one of the major

134 factors explaining the observed differences in the communities across depth.

135 In our study no compartment effect was detected for the communities (PERMANOVA,

$136 F_{2,16}=0.68, P=0.66$ ), besides the mentioned change in relative abundance of the family

137 Glomeraceae (see above). However, previous studies conducted with the same

138 samples show that bacterial communities exhibit a clear compartmentation in the

139 subsoil (Uksa et al., 2015). This difference might be related to the linear, hyphal growth

140 habit of fungi and their unique ability to integrate over larger soil volumes.

141 We were able to show that subsoil communities are clearly different and not only a

142 subset of topsoil communities, and found contrasting patterns of abundance for

143 different families. Whether this shift in community composition also means a shift in

144 function remains unknown; but the clear difference in dominant families with depth

145 suggests turnover also in functional traits (Powell et al. 2009). Our results emphasize

146 the need to account for subsoil when designing agricultural management strategies

147 and highlight the potential role of deeper soil layers as a biodiversity reservoir. 
150 Acknowledgements

151 MR acknowledges funding through the Federal Ministry of Education and Research

152 (BMBF) initiative 'BonaRes - Soil as a sustainable resource for the bioeconomy' for the

153 project Soil ${ }^{3}$. TC was supported by the project SENSE (Structure and Ecological Niche

154 in the Soil Environment; EC FP7 - 631399 - SENSE). Illumina sequencing was carried

155 out at the Berlin Center for Genomics in Biodiversity Research (BeGenDiv, Berlin,

156 Germany). All authors thank Doreen Fischer and Marta Fogt for their involvement in the

157 sampling and sample preparation processes, respectively. MS-H thanks Margarita

158 Moreno Bayón for constant support.

\section{References}

162 Camacho, C., Coulouris, G., Avagyan, V., Ma, N., Papadopoulos, J., Bealer, K.,

163 Madden, T.L., 2009. BLAST+: architecture and applications. BMC Bioinformatics $164 \quad$ 10, 421. doi:10.1186/1471-2105-10-421

165 Chagnon, P.L., Bradley, R.L., Maherali, H., Klironomos, J.N. 2013. A trait-based 166 framework to understand life history of mycorrhizal fungi. Trends in Plant Science 167 18: 484-491.

168 Hofstetter, V., Clémençon, H., Vilgalys, R., Moncalvo, J.-M., 2002. Phylogenetic 169 analyses of the Lyophylleae (Agaricales, Basidiomycota) based on nuclear and 170 mitochondrial rDNA sequences. Mycological Research 106, 1043-1059.

171 doi:10.1017/S095375620200641X 
172 Kabir, Z. 2005. Tillage or no-tillage: impacts on mycorrhizae. Canadian Journal of Plant 173 Science 85: 23-29.

174 Kanz, C., Aldebert, P., Althorpe, N., Baker, W., Baldwin, A., Bates, K., Browne, P., van 175 den Broek, A., Castro, M., Cochrane, G., Duggan, K., Eberhardt, R., Faruque, N., 176 Gamble, J., Diez, F.G., Harte, N., Kulikova, T., Lin, Q., Lombard, V., Lopez, R., 177 Mancuso, R., McHale, M., Nardone, F., Silventoinen, V., Sobhany, S., Stoehr, P., 178 Tuli, M.A., Tzouvara, K., Vaughan, R., Wu, D., Zhu, W., Apweiler, R., 2005. The 179 EMBL Nucleotide Sequence Database. Nucleic Acids Research 33, D29-33. doi:10.1093/nar/gki098

Kautz, T., Amelung, W., Ewert, F., Gaiser, T., Horn, R., Jahn, R., Javaux, M., Kemna, A., Kuzyakov, Y., Munch, J.C., P??tzold, S., Peth, S., Scherer, H.W., Schloter, M., Schneider, H., Vanderborght, J., Vetterlein, D., Walter, A., Wiesenberg, G.L.B., Köpke, U., 2013. Nutrient acquisition from arable subsoils in temperate climates: A review. Soil Biology and Biochemistry 57, 1003-1022. doi:10.1016/j.soilbio.2012.09.014

Krüger, M., Stockinger, H., Krüger, C., Schüssler, A., 2009. DNA-based species level detection of Glomeromycota: one PCR primer set for all arbuscular mycorrhizal fungi. New Phytologist 183, 212-23. doi:10.1111/j.1469-8137.2009.02835.x

Leifheit, E.F., Veresoglou, S.D., Lehmann, A., Morris, E.K., Rillig, M.C., 2014. Multiple factors influence the role of arbuscular mycorrhizal fungi in soil aggregation-a meta-analysis. Plant and Soil 374, 523-537. doi:10.1007/s11104-013-1899-2

Lekberg, Y., Koide, R.T., 2005. Is plant performance limited by abundance of arbuscular mycorrhizal fungi? A meta-analysis of studies published between 1988 and 2003. New Phytologist 168, 189-204. doi:10.1111/j.1469-8137.2005.01490.x 
2015. Host identity is a dominant driver of mycorrhizal fungal community composition during ecosystem development. New Phytologist 205, 1565-1576. doi:10.1111/nph.13226

Moll, J., Hoppe, B., König, S., Wubet, T., Buscot, F., Krüger, D., 2016. Spatial Distribution of Fungal Communities in an Arable Soil. PLoS ONE 11, 1-17. doi:10.1371/journal.pone.0148130

Muleta, D., Assefa, F., Nemomissa, S., Granhall, U., 2008. Distribution of arbuscular mycorrhizal fungi spores in soils of smallholder agroforestry and monocultural coffee systems in southwestern Ethiopia. Biology and Fertility of Soils 44, 653659. doi:10.1007/s00374-007-0261-3

Oehl, F., Sieverding, E., Ineichen, K., Ris, E.A., Boller, T., Wiemken, A., 2005. Community structure of arbuscular mycorrhizal fungi at different soil depths in extensively and intensively managed agroecosystems. New Phytologist 165, 273283. doi:10.1111/j.1469-8137.2004.01235.x

Powell, J.R., Parrent, J.L., Hart, M.M., Klironomos, J.N., Rillig, M.C., Maherali, H., 2009. Phylogenetic trait conservatism and the evolution of functional trade-offs in arbuscular mycorrhizal fungi. Proceedings of the Royal Society B: Biological Sciences 276, 4237-45. doi:10.1098/rspb.2009.1015

R Core Team, 2016. R: A language and environment for statistical computing. $R$ Foundation for Statistical Computing, Vienna, Austria.

Smith S. E., Read D., 2008. Mycorrhizal Symbiosis, 3rd Edn. San Diego, CA: Academic Press.

Smith, S.E., Smith, F.A., 2011. Roles of Arbuscular Mycorrhizas in Plant Nutrition and Growth: New Paradigms from Cellular to Ecosystem Scales. Annual Review of 
Spatafora, J.W., Chang, Y., Benny, G.L., Lazarus, K., Smith, M.E., Berbee, M.L., Bonito, G., Corradi, N., Grigoriev, I., Gryganskyi, A., James, T.Y., O’Donnell, K., Roberson, R.W., Taylor, T.N., Uehling, J., Vilgalys, R., White, M.M., Stajich, J.E., 2016. A phylum-level phylogenetic classification of zygomycete fungi based on genome-scale data. Mycologia 108, 1028-1046. doi:10.3852/16-042

Uksa, M., Fischer, D., Welzl, G., Kautz, T., Köpke, U., Schloter, M., 2014. Community structure of prokaryotes and their functional potential in subsoils is more affected by spatial heterogeneity than by temporal variations. Soil Biology and Biochemistry 75, 197-201. doi:10.1016/j.soilbio.2014.04.018 Fischer, D., 2015. Prokaryotes in subsoil-evidence for a strong spatial separation of different phyla by analysing co-occurrence networks. Frontiers in Microbiology and plant genotype effects on the formation of arbuscular mycorrhiza in Avena sativa and Avena nuda at different soil depths. Biology and Fertility of Soils 46, 


\section{Figures}

245 Fig. 1 Relative abundance of reads per family in different soil compartments.

246 Proportion of reads assigned to each family for depth (panel A), compartment (B) and

247 depth and compartment (C). Families are coded by color. The category "Others"

248 comprises the families Ambisporaceae, Archaeosporaceae, Gigasporaceae and

249 Paraglomeraceae, as well as OTUs assigned only at the subphylum level. Topsoil =

$25010-30 \mathrm{~cm}$, subsoil $=60-75 \mathrm{~cm}$. Extended results are presented in the supplementary

251 materia

A.

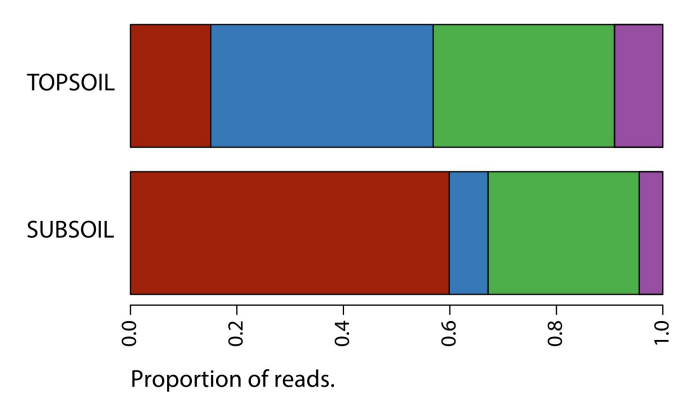

c.
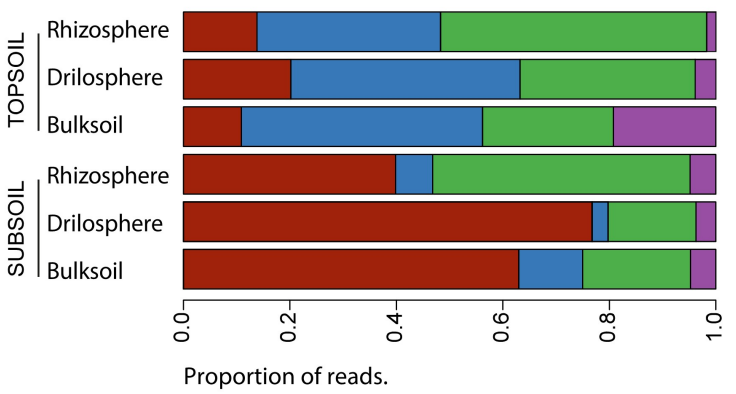
Rhizosphere Drilosphere Bulksoil

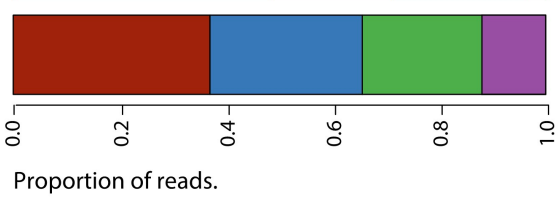
Proportion of reads.

253 Fig. 2 Relative abundance of the 10 most abundant OTUs for each soil

254 compartment. Relative abundance of the OTU is represented by the area of the 255 square (see scale below figure panel). The OTU list corresponds to the 10 most 256 abundant OTUs for each environment. Topsoil $=10-30 \mathrm{~cm}$, subsoil $=60-75 \mathrm{~cm}$. 257 Taxonomic assignment of each OTU is given (also see Table 


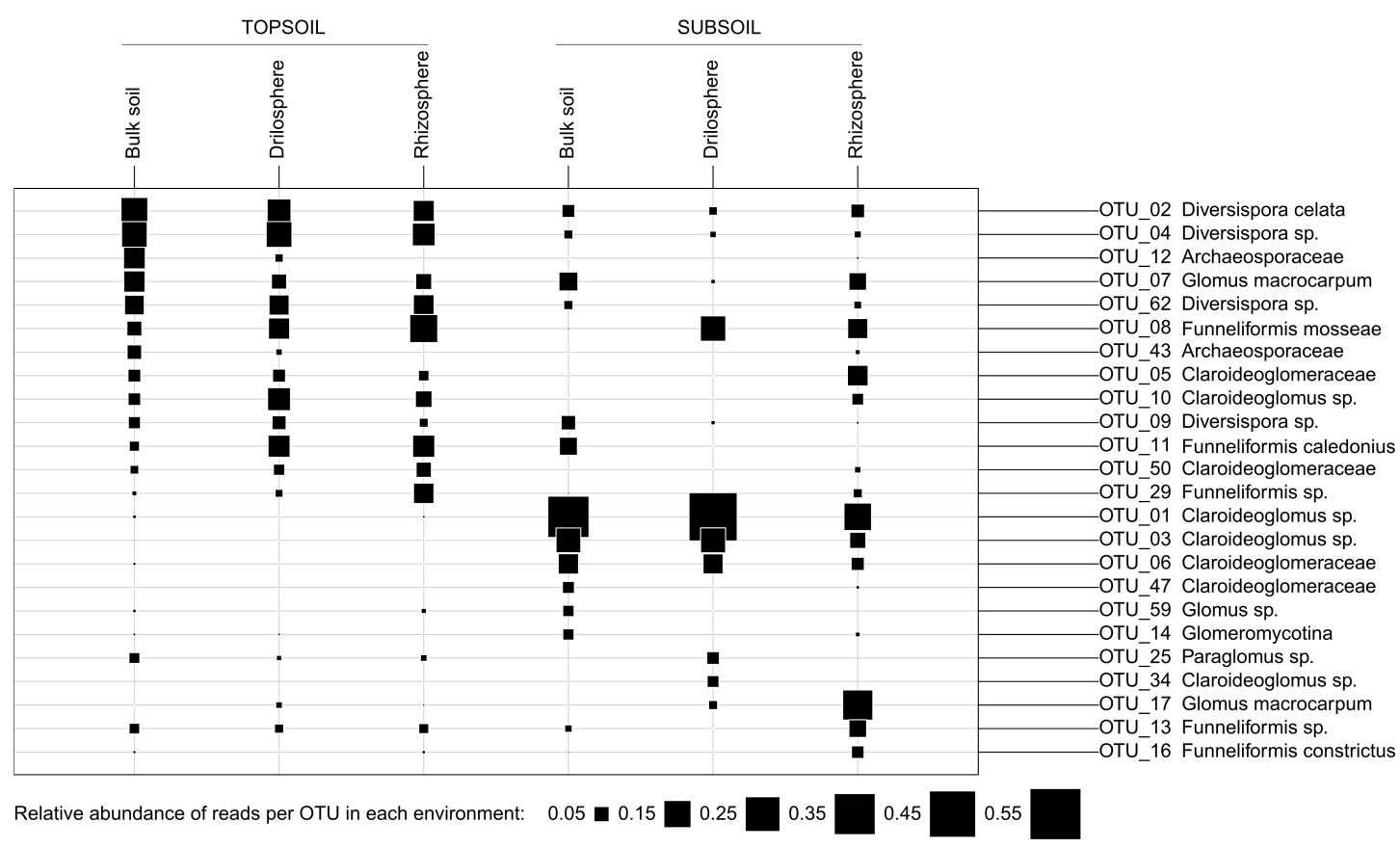

261 Fig. 3 Community ordination of AMF in different soil compartments. Non-metric

262 multidimensional scaling (NMDS) of Bray-Curtis pairwise community dissimilarities.

263 The OTU table was normalized to the minimum amount of reads per sample. Ellipses

264 represent one standard deviation around the centroid of each soil depth. Lines link

265 each sample to the centroid of the group. Topsoil $=10-30 \mathrm{~cm}$, subsoil $=60-75 \mathrm{~cm}$.

266 Depth is coded by color and compartment by symbol shape. 
bioRxiv preprint doi: https://doi.org/10.1101/212597; this version posted November 1, 2017. The copyright holder for this preprint (which was not certified by peer review) is the author/funder, who has granted bioRxiv a license to display the preprint in perpetuity. It is made available under aCC-BY-NC-ND 4.0 International license.

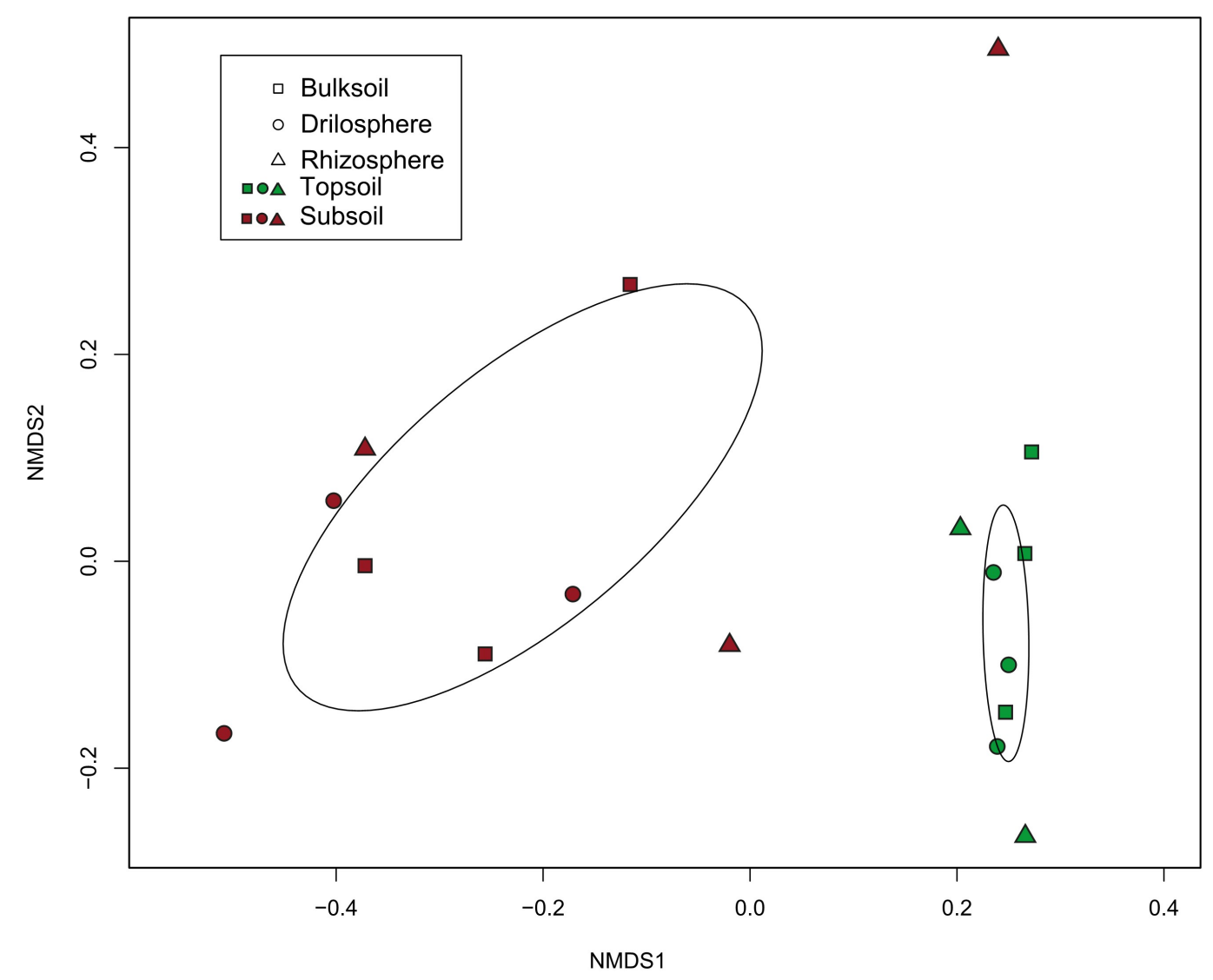

267 